\title{
Implementation considerations when expanding health worker roles to include safe abortion care: a five-country case study synthesis
}

Claire Glenton ${ }^{1 *}\left(\mathbb{D}\right.$, Annik M. Sorhaindo², Bela Ganatra ${ }^{3}$ and Simon Lewin ${ }^{4}$

\begin{abstract}
Background: Allowing a broader range of trained health workers to deliver services can be an important way of improving access to safe abortion care. However, the expansion of health worker roles may be challenging to implement. This study aimed to explore factors influencing the implementation of role expansion strategies for non-physician providers to include the delivery of abortion care.

Methods: We conducted a multi-country case study synthesis in Bangladesh, Ethiopia, Nepal, South Africa and Uruguay, where the roles of non-physician providers have been formally expanded to include the provision of abortion care. We searched for documentation from each country related to non-physician providers, abortion care services and role expansion through general internet searches, Google Scholar and PubMed, and gathered feedback from 12 key informants. We carried out a thematic analysis of the data, drawing on categories from the SURE Framework of factors affecting the implementation of policy options.

Results: Several factors appeared to affect the successful implementation of including non-physician providers to provide abortion care services. These included health workers' knowledge about abortion legislation and services; and health workers' willingness to provide abortion care. Health workers' willingness appeared to be influenced by their personal views about abortion, the method of abortion and stage of pregnancy and their perceptions of their professional roles. While managers' and co-workers' attitudes towards the use of non-physician providers varied, the synthesis suggests that female clients focused less on the type of health worker and more on factors such as trust, privacy, cost, and closeness to home. Health systems factors also played a role, including workloads and incentives, training, supervision and support, supplies, referral systems, and monitoring and evaluation. Strategies used, with varying success, to address some of these issues in the study countries included values clarification workshops, health worker rotation, access to emotional support for health workers, the incorporation of abortion care services into pre-service curricula, and in-service training strategies.
\end{abstract}

Conclusions: To increase the likelihood of success for role expansion strategies in the area of safe abortion, programme planners must consider how to ensure motivation, support and reasonable working conditions for affected health workers.

Keywords: Reproductive health, Abortion, Health systems, Human resources for health, Task shifting, Role expansion, Implementation, Service delivery

* Correspondence: claire.glenton@fhi.no

${ }^{1}$ Global Health Unit, Norwegian Institute of Public Health, Oslo, Norway

Full list of author information is available at the end of the article 


\section{Background}

Allowing a broader range of trained health workers to deliver safe abortion care is one way of improving access to these services. However, the expansion of health worker roles in abortion care may be challenging to implement, at least initially. This paper presents the results of a multicountry case study synthesis where we explore factors that may influence the implementation of the expansion of health worker roles to include abortion care services in five countries: Bangladesh, Ethiopia, Nepal, South Africa, and Uruguay. We undertook this synthesis to inform the World Health Organization (WHO) guidelines on "Health worker roles in providing safe abortion care and postabortion contraception" [1]. These guidelines provide evidence-based recommendations about the inclusion of a range of health workers in the delivery of abortion, postabortion care and post-abortion contraception.

Ethiopia, Nepal, South Africa and Uruguay currently permit abortion in a broad range of circumstances [2-9]. While abortion law per se is restrictive in Bangladesh, menstrual regulation is defined as the evacuation of the uterus of a woman at risk of being pregnant to ensure a state of non-pregnancy [10], and is not regulated by the penal code restricting abortion [10].

In all five countries, abortion care services are provided as part of the formal healthcare system. In addition to care delivery by obstetricians, gynaecologists and non-specialist physicians, a variety of healthcare professionals provide these services, including midwives, nurses and auxiliary nurses. In Nepal and Ethiopia, governments also use lay or community health workers to perform certain supportive tasks related to abortion care such as community education and referral to health facilities $[11,12]$.

The increased use of non-physician providers to deliver healthcare services is typically regarded as a promising strategy for improving access to healthcare. However, such role expansion constitutes a complex intervention that has a number of implications for health workers, for women, and for the organisation of care. The objective of this study was to explore factors influencing the implementation at scale of non-physician provider role expansion to include the delivery of abortion care services.

\section{Methods}

We conducted a multi-country case study synthesis based on data from five countries. The case-study approach involves analysing phenomena in 'real life' settings by using a range of different types of evidence. This approach can be particularly useful when the goal is to compare and explore processes within and across settings $[13,14]$.

\section{Country selection}

Through consultation with experts, we selected countries with at-scale, national programmes that used non- physician providers to deliver some of their abortion care services; were located in Africa, Asia and South America; had been running for at least 5 years; and had a reasonable level of documentation available in English or Spanish. Non-physician providers can include a range of healthcare providers, including associate clinicians, midwives, auxiliary nurse midwives, nurses, auxiliary nurses and lay health workers. Given the resourceintensive nature of the related data collection and analysis, we limited ourselves to five countries: Bangladesh, where the menstrual regulation programme was established in 1979; and South Africa, Nepal, Ethiopia and Uruguay, where the current abortion programmes were established in 1996, 2002, 2005 and 2012 respectively.

\section{Data collection, analysis and synthesis}

We searched for written documentation, including evaluation reports and academic study reports, about factors affecting abortion care delivery and role expansion in each country after the introduction of their national abortion programme. We searched using general internet searches; through Google Scholar and PubMed (see Additional file 1); and by searching the reference lists of included documents. Our search was carried out in May 2014 and repeated in November 2016. In addition, we purposively sampled 12 key informants from non-governmental and governmental organisations and research institutions who had been involved in the implementation and / or assessment of the abortion care programmes in the five countries. We invited these key informants to contribute to the case study synthesis in order to contribute to the WHO Guidelines on abortion care. We asked each key informant to give feedback to our preliminary analysis of the written reports, and to provide any additional written resources. In addition, we asked each key informant to clarify issues that were unclear in the written documentation and to offer additional factors they thought may have influenced the implementation of role expansion strategies in these programmes. We communicated with key informants through phone or skype meetings lasting from $30 \mathrm{~min}$ to one and a half hours and/or through email.

The conceptual framework of this study was based on the SURE (Supporting the Use of Research Evidence) framework. The framework, which provides a comprehensive list of possible factors that may influence the implementation of health system interventions [15] was used to develop our data extraction sheet and informed our analysis (see Table 1).

CG or AS read each of the included documents and extracted any data that described factors tied to the implementation of abortion care delivery as it relates to role expansion, and summarised these. CG and AS then read and re-read the data summaries, identified key themes, and discussed the definitions and boundaries of 
Table 1 Using the SURE Framework to identify factors affecting the implementation of role expansion for abortion care

\begin{tabular}{|c|c|c|}
\hline Level & $\begin{array}{l}\text { Factors affecting implementation of policy } \\
\text { options included in the SURE Framework [15] }\end{array}$ & $\begin{array}{l}\text { Factors affecting the implementation of role expansion } \\
\text { for abortion care identified in this study }\end{array}$ \\
\hline \multirow[t]{3}{*}{ Recipients of care } & Knowledge and skills & \\
\hline & $\begin{array}{l}\text { Attitudes regarding programme acceptability, } \\
\text { appropriateness and credibility }\end{array}$ & $\begin{array}{l}\text { Women's attitudes to and experiences of different } \\
\text { types of health workers }\end{array}$ \\
\hline & Motivation to change or adopt new behaviour & \\
\hline \multirow[t]{3}{*}{ Providers of care } & Knowledge and skills & $\begin{array}{l}\text { Health workers' knowledge about abortion legislation } \\
\text { and services }\end{array}$ \\
\hline & $\begin{array}{l}\text { Attitudes regarding programme acceptability, } \\
\text { appropriateness and credibility }\end{array}$ & $\begin{array}{l}\text { Health workers' willingness to provide abortion care } \\
\text { Health workers' understanding and use of conscientious } \\
\text { objection }\end{array}$ \\
\hline & Motivation to change or adopt new behaviour & \\
\hline \multirow[t]{3}{*}{ Other stakeholders } & Knowledge and skills & \\
\hline & $\begin{array}{l}\text { Attitudes regarding programme acceptability, } \\
\text { appropriateness and credibility }\end{array}$ & Co-workers' attitudes towards role expansion \\
\hline & Motivation to change or adopt new behaviour & \\
\hline \multirow[t]{19}{*}{ Health system constraints } & Accessibility of care & \\
\hline & Financial resources & \\
\hline & Human resources & \\
\hline & $\begin{array}{l}\text { Educational and training system, including } \\
\text { recruitment and selection }\end{array}$ & Health worker training \\
\hline & $\begin{array}{l}\text { Clinical supervision, support structures and } \\
\text { guidelines }\end{array}$ & Health workers' access to supervision and emotional support \\
\hline & Internal communication & \\
\hline & External communication & \\
\hline & Allocation of authority & \\
\hline & Accountability & Monitoring and evaluation of health workers \\
\hline & Community participation & \\
\hline & Management and/or leadership & \\
\hline & Information systems & \\
\hline & Scale of private sector care & \\
\hline & Facilities & \\
\hline & Patient flow processes & Health workers' access to referral systems \\
\hline & Procurement and distribution systems & Health workers' access to supply chains \\
\hline & Incentives & Health worker workloads and incentives \\
\hline & Bureaucracy & \\
\hline & Relationship with norms and standards & \\
\hline \multirow[t]{9}{*}{ Social and political constraints } & Ideology & \\
\hline & Governance & \\
\hline & Short-term thinking & \\
\hline & Contracts & \\
\hline & Legislation or regulation & \\
\hline & Donor policies & \\
\hline & Influential people & \\
\hline & Corruption & \\
\hline & Political stability and commitment & \\
\hline
\end{tabular}


each emerging theme and how these themes related to the SURE framework. BG and SL commented on emerging themes. CG and AS also went through all feedback from key informants. We categorised similar themes that emerged from different countries together within the relevant SURE framework category.

\section{Results}

We included and extracted data from 67 written reports and feedback from 12 key informants (see Fig. 1 Flow diagram; and Additional file 2 Overview of documents that contributed to the synthesis findings). Our final analysis was based on 14 reports and feedback from two key informants from Bangladesh, ten reports and feedback from three key informants from Ethiopia, 20 reports and feedback from one key informant from Nepal, 19 reports and feedback from four key informants from South Africa, and four reports and feedback from two key informants from Uruguay. While some of the reports were descriptions or opinion pieces, most were published academic study reports or programme evaluation reports, and most had used qualitative semi-structured interviews or quantitative surveys to collect data.

Very few of the reports focused on the topic of role expansion specifically, but dealt more generally with factors affecting the delivery of abortion care services. However, these factors are important to the success of any role expansion strategy and so are discussed below. All of the reports gave some information about factors affecting abortion care service delivery by non-physician providers. However, several of these reports combined this information with information about specialist and non-specialist doctors. In the results section, we have used the term "health workers" to refer to data from reports that deal

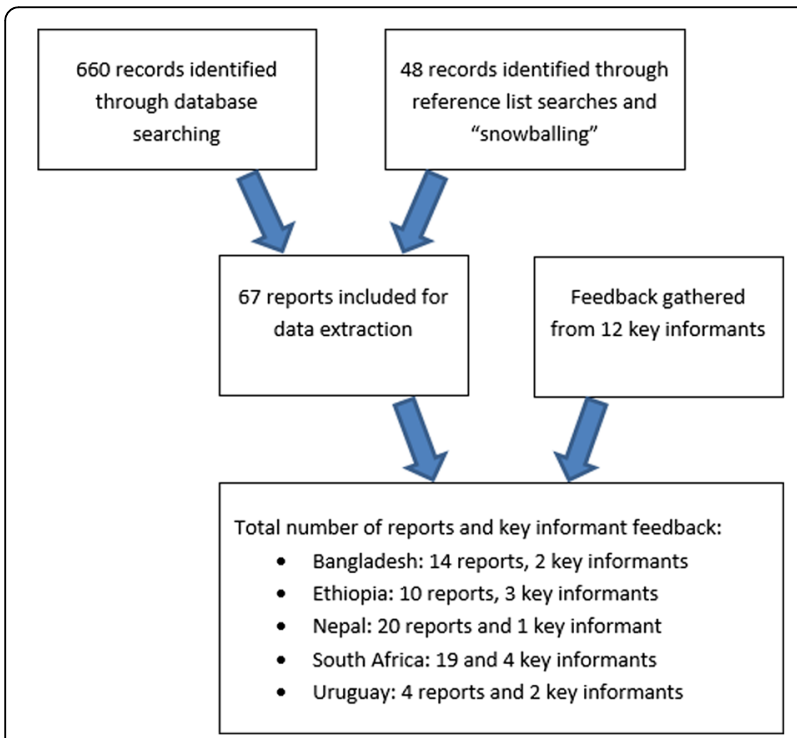

Fig. 1 Flow diagram with either non-physician providers only or non-physician and physician providers in combination.

We identified a number of factors that appeared to have influenced the implementation of non-physician provider role expansion for abortion care services in the five countries. Some of these factors were only mentioned briefly, including factors tied to health worker accreditation. In this paper we focus on factors that may have influenced health workers' inclusion in the delivery of abortion care once legal and accreditation requirements in their settings had been fulfilled. These factors included willingness to provide abortion care; health workers' knowledge about abortion legislation and services; managers' and co-workers' attitudes towards role expansion; women's attitudes to and experiences of different types of health workers; and health systems factors, including workloads and incentives, health worker training and supervision, supply chains and referral systems, and monitoring and evaluation (see Table 1).

\section{Health workers' willingness to provide abortion care}

The success of any role expansion strategy is likely to be influenced by health workers' willingness to take on the new tasks expected of them. Health workers who are reluctant to perform these tasks may either refuse to deliver them or may deliver poor quality care to their clients. Our synthesis suggests that health workers' willingness to provide abortion services varied, and was influenced by a number of factors, including their personal views and beliefs about abortion, the stage of pregnancy and method of abortion, and their perceptions of their professional roles.

\section{Health workers' willingness influenced by their personal views about abortion}

In all five countries, health workers' personal views and beliefs about abortion influenced their willingness to provide abortion care services.

In Nepal, specialist and non-specialist doctors, nurses and auxiliary nurse midwives were reported as being generally supportive of the provision of safe abortion services $[16,17]$, seeing these services as an important contribution to women's health and perceiving their participation in the provision of these services as a way of helping women in need $[18,19]$. Some of them saw a need to increase access to safe abortion services and were concerned about continued unsafe abortion practices $[18,19]$. In South Africa, some doctors, nurses and midwives echoed these sentiments, referring to their own prior exposure to the consequences of unsafe abortion, either professionally or in their personal lives $[20,21]$; to the consequences of raising children in difficult socioeconomic circumstances [21]; and to their support of the woman's right to choose [20,21].

While South African health workers often supported the provision of abortion care, reluctance to provide abortion care because of moral or religious beliefs was 
also commonly reported among these groups [21-27]. Similar resistance was reported, although to a lesser extent, among specialist doctors in Uruguay [28]; among midwives, specialist and non-specialist doctors, nurses and health officers in Ethiopia [29, 30]; and among health workers in Bangladesh [31-35]. Ethiopian health workers in some reports agreed that unsafe abortion was a serious problem and that there was a need for safe abortion services, but their willingness to provide these services varied $[29,30,36]$. Similarly, doctors in one report from Bangladesh supported the use of abortion care services as a way of achieving the government's population control objectives, but preferred not to perform these services themselves [37].

While health workers' personal views towards abortion were mixed, reports from all five countries indicated that health workers were likely to regard some reasons for seeking abortion as more legitimate than others. For instance, some health workers, including nurses, midwives and doctors, found abortion more acceptable if it was due to rape, incest, foetal abnormalities, serious illness or economic hardship [21, 36, 38-41]. Conversely, health workers in some settings were reported as being less sympathetic and more judgmental towards young, unmarried girls seeking abortion $[18,33,42]$. In one Nepalese report, doctors and nurses supported the ban on sex-selective abortions, but acknowledged the pressure women were under to have male children and were concerned that women would seek illegal abortions if turned away [19].

\section{Health workers' willingness influenced by the method of abortion and stage of pregnancy}

Health workers' experiences of and willingness to provide abortion care services were also influenced by the method of abortion and the stage of pregnancy. While health worker perceptions about the effectiveness of medical abortion compared to other methods sometimes varied, nurses and other health workers in reports from South Africa, Ethiopia and Nepal regarded it as simpler to perform [4345]. Some also found medical abortion more acceptable because they saw it as requiring less of an active role by the provider in managing the abortion process $[12,46]$.

In South Africa, Ethiopia and Nepal, some specialist and non-specialist doctors, facility managers and other health workers were reported as feeling uncomfortable with the provision of second-trimester abortions [21, 47, 48], often because they found it traumatic to deal with the foetus $[12,21,24]$. In one South African report, midwives involved in second-trimester medical abortions described feeling emotionally unprepared and alone as they were often left unsupported after the doctor had prescribed the drug [39]. These midwives described not wanting to be alone with the woman and the foetus, and appreciated company, even if that person did nothing other than provide moral support [39]. In Ethiopia, midwives or nurses taking care of the expelled foetus and the mother were typically accompanied by another health worker or other member of staff, including cleaning staff [12]. Based on challenges with the implementation of secondtrimester abortion services experienced in other countries, programme planners in Nepal intentionally delayed the introduction of second-trimester abortion services, both to ensure that providers had good first-trimester abortion skills, and to prepare providers and garner support for second-trimester services, for instance through values clarification workshops (see below) $[6,47,49]$. They also used staff rotation to avoid burnout because of the emotional burden related to second-trimester abortions [47].

\section{Health workers' willingness influenced by their perceptions of their professional roles}

Health workers' willingness to provide abortion care also appeared to be influenced by their perceptions of their professional roles. In some South African reports, nurses described what they perceived to be a conflict between their pledge to preserve life and their identity as carers of mothers and children on the one hand, and their involvement with abortion on the other [27, 38, 39]. In one of these reports, nurses complained that deliveries and abortions were conducted in hospital units directly opposite each other, which served to emphasise this conflict, and nurses believed that abortion should be performed in a separate clinic [27]. However, in Ethiopia, one key informant described midwives as having become more supportive of the provision of abortion care over time, suggesting that the incorporation of safe abortion services into midwives' pre-service training led midwives to regard abortion care as an inherent part of their role as health providers [50]. One report in South Africa also found that some health workers, including midwives and nurses, viewed the provision of abortion as part of a natural career trajectory, and as an opportunity to broaden their skills base [21]. Similarly, in Nepal, after some initial concerns, auxiliary nurse midwives who were trained to provide medical abortions expressed confidence in their skills, and a desire to further broaden their skills in abortion care [11].

\section{Health workers' willingness influenced through values clarification workshops}

In all five countries, efforts were made to increase health workers' willingness to provide abortion care services through educational activities. Workshops were held in Uruguay aiming to build commitment among health workers and administrative personnel [51]. In South Africa, Nepal, Ethiopia and Bangladesh, values clarification workshops were used to garner support for abortion services in general and for second-trimester services in particular [12, 32, 49, 50, 52, 53]. These workshops aimed to educate 
participants about current abortion legislation; allow them to clarify their values and attitudes; encourage change in their attitudes and behaviour towards women seeking an abortion; and ultimately achieve support for the provision of abortion services [20, 21, 26, 49]. Participants suggested that these workshops had been useful in giving them a better understanding of abortion [23] and helped them to acknowledge clients' rights and needs [47]; assisting those opposed to abortion in "viewing things differently" [21], and helping them to feel comfortable when talking about abortion [12]. However, one report from South Africa pointed out that these workshops were not mandatory and there seemed to be little done to encourage attendance [21].

\section{Health workers' access to, knowledge about, and use of conscientious objection}

Health workers seemed to use conscientious objection to opt out of providing abortion care but were not always aware of the limits of the provisions of the law or their legal obligations to ensure that women were not denied care. In South Africa and Uruguay, legislation was in place that allowed health workers to conscientiously object to performing an abortion [5, 8, 54]. However, health workers did not always understand or follow this legislation correctly and guidelines or systems were not always in place to manage the implementation of conscientious objection [5, 8]. In South Africa, health workers in two reports refused to assist in any part of the abortion procedure or provide basic nursing care to abortion clients, citing religious or moral reasons, although they were not entitled to conscientiously object to performing these tasks [21, 27]. In Nepal, Ethiopia and Bangladesh, there was no formal policy for conscientious objection. However, in Nepal, no action was taken towards Nepalese providers who refused to provide abortions based on their conscience [52]. In one report on Ethiopian midwives, most respondents believed that there would be no repercussions for midwives refusing to provide abortion services [30]. In Bangladesh, providers who were unwilling to provide the service were encouraged to refer women elsewhere [32].

\section{Health workers' knowledge about abortion legislation and services}

Health workers taking on new tasks also need to be knowledgeable about which services are available, to whom, and under what circumstances. However, health worker knowledge about abortion legislation and services varied across settings. In Uruguay, informants suggested that there was widespread knowledge about the law among all health workers, both because of access to training [54] and because of the high-profile legal battles about conscientious objection and denial of care to women due to health system delays that push them beyond the pregnancy stage at which legal abortions are allowed [28]. In South Africa, Ethiopia,
Nepal and Bangladesh, on the other hand, knowledge about legislation and available abortion services among health workers appeared to vary but was often described as lacking, both among health workers who provided abortion care and those who did not $[9,18,21,29,30,32,36,40,49$, 55-58]. This apparent lack of awareness had consequences for women's access to services. For instance, in Bangladesh, some health workers were unaware that second-trimester abortions were legal in certain circumstances and therefore refused to perform the service [32] while some Nepalese health workers wrongly believed that women needed their husbands' permission to obtain an abortion [18]. In Nepal, particular efforts were therefore made in training programmes for auxiliary nurse midwives to ensure that they would provide services to all women, including young, unmarried women [59].

\section{Managers' and co-workers' attitudes towards role expansion}

Role expansion strategies also affect co-workers, including those responsible for managing or supervising the health workers that have been given new tasks, and those who have previously delivered the services in question. Managers' and co-workers' views on non-physician provider role expansion varied within and across settings. In Nepal, Bangladesh and Ethiopia, specialist and non-specialist doctors, health officers and others were reported as being positive towards the use of non-physician providers to provide abortion services [37, 60-63]. In Bangladesh, one report suggests that doctors' own reluctance to provide abortions, either on religious grounds or because they felt that menstrual regulation was "medically unsophisticated", may have contributed to their willingness to allow non-physician providers to take on this task [37]. Facility managers in one Nepalese report were also positive towards the use of nurses in the provision of first trimester abortion care services, indicating that this could improve continuity of care, decrease the burden on doctors, increase retention of nurses and increase patient satisfaction with health services [64].

However, in the same Nepalese study, there were also some concerns about nurses' inability to manage severe complications [64]. In reports from Bangladesh and Ethiopia, specialist and non-specialist doctors, nurses and health officers also had some concerns about the safety and effectiveness of using non-physician providers and the lack of good referral systems [37, 63]. In Uruguay, one informant referred to "turf protection" where specialist doctors were reluctant to delegate tasks, such as prescribing abortion medication, to other health workers because they did not feel that these health workers were qualified to provide the service [28]. However, this informant also pointed out that in Uruguay, which is a highly urban country with a high physician to population ratio, few tasks are shared with non-physicians [28]). 
In some studies, non-physician providers also experienced resistance from co-workers because of their personal views on abortion. In South Africa, some nurses, midwives, specialist and non-specialist doctors described feelings of rejection, stigma and negative comments because of their work from colleagues who did not provide abortion care [21, 23, 24, 44, 65], particularly when delivering second-trimester abortions [24]. In Bangladesh, some menstrual regulation providers were reported as feeling demoralised by the discrimination and abuse they received from colleagues [32].

\section{Women's attitudes to and experiences of different types of health workers}

The success of role expansion strategies may also be influenced by how service users perceive the use of new types of health workers. Several reports noted that women in the five countries were generally satisfied with abortion services and abortion service providers [11, 28, 66-69], although there were also complaints of poor treatment of women [27, 28, 43, 44, 69, 70]. However, women's attitudes and experiences towards service providers tended not to focus on the category of health worker and his or her level of training. Instead, women primarily referred to issues such as knowing and trusting the health worker, kindness and caring, being able to speak the same language, confidentiality and privacy, cost and closeness to home [33, 63, 67-69, 71-73]. In at least one report, female health workers were also preferred over male health workers [74]. In Bangladesh, the presence or absence of these factors led some women to prefer informal providers [33, 71, 72], while in Nepal and Ethiopia, lay health workers were sometimes preferred for similar reasons $[63,75]$.

\section{Health system factors}

The success of role extension strategies is also likely to depend on the ability of the health system to adapt to the organisational implications of these strategies. Reports from the five countries suggest that the successful use of non-physician providers could be influenced by health worker workloads and incentives, training and supervision, supply chains and referral systems, and monitoring and evaluation systems.

\section{Health worker workloads and incentives}

The inclusion of abortion services often had an impact on non-physician providers' workload. In Ethiopia, midwives who were asked to take on abortion services complained, particularly in the beginning of the programme, that they were being burdened with the doctors' tasks [12, 50, 76]. In South Africa, one report described how an increase in access to abortions had not been matched with an increase in healthcare facility staff [77], and increased workloads were referred to as one reason for not taking on abortion services among South African nurses [38, 44]. In Uruguay, facilities hired new staff to come in line with the new abortion legislation or redistributed staff where conscientious objection impeded service provision, but a lag between the change in legislation and facilities' readiness to provide services was initially reported [28].

A related complaint was that increases in health worker workloads were not always reflected in health worker incentives. In South Africa, nurses and midwives indicated that they would be more willing to provide abortion services if they were to receive additional incentives, and expressed frustration that their additional training and certification had not led to an increase in pay [46].

\section{Health worker training}

The inclusion of abortion care services also had implications for health worker training. The extent to which abortion care had become part of the curriculum in medical, nursing or midwifery schools varied across countries $[6,19,22,48,50,54,78]$. In Bangladesh, pre-service training in some abortion care services was offered to family welfare visitors, nurses, nurse-midwives and midwives, but pre-service training institutions were reported to suffer from a lack of skilled teachers and teaching tools and few opportunities for hands-on clinical training [78].

The reports suggest that most attention was paid to inservice training. For instance, in South Africa and Nepal, a cascade model or "Training of trainers" approach was used to train abortion providers as efficiently and rapidly as possible $[2,6,79,80]$. However, the implementation of in-service training posed a number of challenges. In Nepal, healthcare facilities that were used as training centres often found the dual demands of training and regular service provision too demanding $[6,79]$. In Ethiopia, a pilot report that aimed to train lay health workers to deliver medical abortions at health posts was made difficult because of an insufficient number of cases at this level of care [68]. In Nepal, South Africa and Ethiopia, nurses, midwives and other health workers working in facilities with staff shortages reported difficulties getting work release to attend training $[6,21,44,68]$, while communitybased lay health workers in Nepal found it difficult to attend the few training opportunities they were given due to other commitments [75]. South African abortion providers were also reported as avoiding abortion training because of stigma from colleagues [21]. In South Africa, Nepal, Ethiopia and Bangladesh, the government collaborated with the private sector and with NGOs to increase capacity and provide training in abortion care $[2,12,21$, $32,33,57,79]$. However, one report in Bangladesh described variations and inconsistencies in training length and content between the different NGO training programmes and some policy makers called for a common training curriculum [33]. 


\section{Health workers' access to supportive supervision}

Access to supportive supervision, including emotional support from colleagues was acknowledged as important for abortion service providers, but was sometimes reported as lacking [35, 64, 81, 82]. In one report in Bangladesh, supervisors in the public sector were said to struggle with a lack of skills, tools and checklists, although NGOs were described as having strong supervisory procedures [33]. In Ethiopia, partner NGOs were also reported as providing regular supportive supervision, at least in certain areas of the country [50], where a standard checklist was used, feedback was given on the spot and support was provided [12]. However, the long-term sustainability of support from NGOs was reported as a concern [12]. One report from Nepal described how the government worked with a partner NGO to establish long-term support systems for auxiliary nurse midwives by developing teams of local stakeholders whose role it was to maintain regular contact and offer support to these providers [59].

In addition to managerial supervision and support, the reports referred to the importance of support in dealing with the emotional challenges of the work [23, 27, 83, 84]. In one Nepalese report, nurses described feeling supported by managers, doctors and other nurses [64] while in some South African reports, informal support was sometimes available, either from other abortion providers or nonproviders [40, 65]. However, the South African reports in particular highlighted a lack of psychological support [23] and a lack of support from managers $[39,40,65]$ doctors and the authorities [77]. Support was called for not just at regular intervals, but immediately after a difficult emotional experience [65], and health workers suggested that this could come from colleagues, managers, psychologists or priests [23]. Different solutions were used to offer such support. In Ethiopia, abortion providers from different healthcare facilities were linked to each other so that they could share their experiences and support each other [12]. In South Africa, formal support, for instance through support groups and debriefing sessions, was sometimes offered, particularly in the initial stages of the abortion programme [46]. Health workers also appreciated informal emotional support from colleagues. For instance, working together with a colleague during difficult abortion procedures was described as minimising feelings of loneliness while sharing experiences with colleagues provided an outlet for their emotions [39].

\section{Health workers' access to supplies and referral systems}

While the adoption of abortion care services by nonphysician providers allows abortion care services to be offered at a broader range of facilities, this requires that these providers have good access to supplies and referral systems. In Nepal, Bangladesh and Ethiopia, poorly equipped facilities and poor access to supplies and drugs were sometimes reported as a problem, particularly for abortion care providers working at primary level and in peripheral areas $[6,9,33,50,75,85]$. In Nepal, while poor supply chain management was one reason for this, the USA's Helms Amendment, which limits the use of US foreign assistance for abortion, also presented challenges for abortion supply logistics [6]. In reports from Bangladesh, Ethiopia and Nepal, referring women on for further abortion care also had its challenges, sometimes reflecting general weaknesses in the country's referral systems, including a lack of health workers to refer on to [31, 50, 86]. In one report, Nepalese lay health workers offering pregnancy tests to women were expected to refer women on for abortion services or antenatal care but found referral cards difficult to use and instead accompanied women to health facility appointments [75].

\section{Monitoring and evaluation of health workers}

Monitoring and evaluation may be particularly important after new tasks have been introduced, and different approaches were used to monitor and evaluate health worker performance and encourage service improvement. In Uruguay, a monitoring and evaluation tool was applied once every 6 months. This involved observations of counselling sessions and an interview with the client followed by meetings with the health worker teams to explain the findings and help to improve the service [54]. In Ethiopia, annual review meetings were conducted where health managers, health workers and facility heads were given the opportunity to discuss their successes and challenges and come up with action points [12]. In Nepal, managers at abortion facilities were trained to use performance improvement checklists to help them identify problems, for instance with regard to staff skills and motivation and facility supplies and functioning, and to develop action plans to address these issues [6]. However, obtaining accurate monitoring data could be challenging as record keeping was often poor, especially when staff were overburdened or where they rotated between different departments $[6,79]$. For the Nepalese lay health workers, monitoring and evaluation was further complicated by low literacy levels, although self-reporting of activities during monthly meetings has been one solution to this problem [75]. Another challenge in Nepal was the fact that private facilities had no reporting obligations, making their monitoring data unavailable to the government [6]. Technical and logistical problems and lack of training were also reported in the monitoring and evaluation of menstrual regulation services in Bangladesh [32, 33].

\section{Discussion}

By increasing the types of health worker that can deliver services such as abortion care, services can be delivered by more health workers and at a wider range of facilities, 
thereby bringing services closer to the people who need them and giving more people access to these services. Once they have been adequately trained, health workers in primary or community care may also be particularly well suited to deliver these services because of closer links to the communities they serve, for instance through better language skills and a better understanding of their clients [87], and because more people have access to these health workers.

Many of the challenges of role expansion in abortion care are similar to other types of health care services. Our synthesis highlights challenges that have been documented for health worker role expansion in abortion care in other countries [88], as well as for other areas of healthcare, including maternal and child health and HIV [89-93]. These include concerns about access to supplies and functioning referral systems when tasks are moved to new levels of facilities [89, 90], problems in ensuring that health workers taking on new roles are sufficiently trained and supervised [89-93], and implications for health worker workloads and salaries [89-93]. However, these challenges reflect the broader weaknesses of many healthcare systems, and are likely to require increased resources and changes to these systems at a far wider level than for abortion programmes alone.

Our synthesis also highlights issues that may be unique to or particularly relevant for abortion services. In contrast to many other health issues, abortion is a topic of debate in most settings. People's attitudes towards abortion are likely to be influenced by their moral or religious beliefs, their views and experiences regarding woman's roles and women's rights, and their views of the rights of women and the foetus [94]. As members of society, health workers are also part of this discourse. In addition, health workers' attitudes may be influenced by what they regard to be their professional roles; their experiences of stigma and support, of women seeking abortions, and of the procedure itself. Together, these factors may influence health workers' willingness to provide abortion care services or to support colleagues carrying out these services, as demonstrated here and in evidence from other countries [88].

As is the case for other types of health worker role expansion, it is essential that health workers taking on abortion care services are properly trained to ensure that services are technically sound. The use of in-service training is particularly relevant when new tasks are introduced or standards updated. However, our synthesis shows that in-service training can be difficult to implement. In addition, the effects of most kinds of in-service training and other implementation strategies on quality of care are generally modest [95]. The incorporation of abortion care services into pre-service curricula appears to have been given less attention, but may be an important training opportunity. In addition, pre-service training may help shape health workers' perceptions of their professional roles [96].
For abortion programmes to have access to enough health workers, and for women to be treated with respect and compassion, health workers also need to be willing and motivated. Technical training alone is therefore unlikely to be sufficient. Our findings suggest that training should also provide abortion care providers with a thorough understanding of the circumstances that may lead women to seek an abortion and an understanding of women's legal rights. The use of values clarification workshops may be one way of addressing this issue [49]. However, it may be important to involve all facility staff, including non-clinical staff, and to encourage participation or make participation mandatory.

While different types of training can potentially influence health workers' willingness to provide abortion care, this willingness may be tested by challenges in their everyday work. Our synthesis and other studies suggest a number of ways in which abortion care providers' working conditions could be improved. One suggestion made by nurses in our synthesis was that abortion services should be provided in separate facilities from labour wards [27]. However, it has also been suggested that women may prefer the increased anonymity that general facilities can offer [97]. In addition, it has been argued that a separation of abortion services from mainstream healthcare services further marginalises abortion and abortion providers [98]. The effects of these and other strategies for improving the working conditions of health workers delivering abortion care need to be evaluated, and should consider the impacts on both women and health workers. Other strategies referred to in our synthesis include the use of health worker rotation; access to emotional support from colleagues or supervisors; and ensuring that health workers carrying out second-trimester abortions are not expected to do this alone. The importance of this type of support has also been referred to by nurses in other studies [99-101].

Despite their best efforts, programme managers may still find that health workers are unwilling to participate in abortion care. Opportunities to opt out varied across the five countries, and the advantages and disadvantages of formal procedures for conscientious objection compared to more informal solutions is unclear from the data. The WHO guidelines on health worker roles in abortion care recommend that "(c)onscientious objection, where allowed, should be regulated, and provision of alternate care for the woman provided" [1]. Our synthesis suggests that health workers in some settings need to be better informed about their options and that formal systems may need better enforcement.

\section{Study strengths and limitations}

Many of the studies we identified focused on the delivery of abortion care services by both physicians and non-physician providers, and did not focus on role expansion specifically. We therefore had to make some assumptions about how factors affecting the implementation of abortion care service 
delivery by both physicians and non-physicians would apply to role expansion strategies among non-physician providers.

Another challenge was the fragmented nature of the data. Many of the reports we identified offered only snapshots from different parts of each country or at different stages in each programme's history. This made it difficult to create a coherent understanding of the programmes and to identify processes within programmes over time. For instance, we were not able to gain a good overview of factors that were present when the programmes were introduced and the extent to which these factors changed as the programmes matured. In general, the reports also aimed to answer different questions than our own, with few of the reports focusing on role expansion to nonphysician providers specifically. Both of these challenges have been noted before in syntheses of this kind [90].

Another challenge was that the included documents offered varying levels of detail regarding how the data had been collected and analysed and were based on a range of different study designs. This variation implied that it was not possible to apply standardised assessment tools to appraise the quality of each documentation source.

The amount of data that we were able to identify for each country also varied. Reports from Uruguay were particularly limited, which may have reflected the relatively short period of time since the programme was established but may also be a result of our search strategies, which may have biased us towards English language sources of information.

We were, however, able to identify a relatively broad set of materials for the programmes, including programme evaluations and academic studies conducted at different points in the programme lifespan and we supplemented these with feedback from key informants. We also attempted to ensure that these key informants reviewed our final analysis. This allowed for the triangulation of sources, methods and timeframes, and strengthened the validity of our findings.

\section{Conclusions}

The World Health Organization recommends a range of strategies to expand health worker roles in the delivery of abortion and post abortion care services [1]. To increase the likelihood of success for these strategies, programme planners need to consider how they can build willingness and motivation among health workers, and create working conditions that ensure the provision of high-quality and compassionate services to the women who need them.

\section{Addition files}

Additional file 1: Search strategy. (DOCX $14 \mathrm{~kb}$ )

Additional file 2: Documents that contributed to the findings reported in this paper. (DOCX 29 kb)

\section{Acknowledgements}

The authors gratefully acknowledge Marijke Alblas, Aster Berhe, Dr. Tapash Ranjan Das, Dr. Demeke Desta, Mosotho Gabriel, Diane Cooper, Jane Harries, Sarah Jane Holcombe, Ana Labandera Monteblanco, Martha Silva, Sharmin Sultana and Anand Tamang who shared their insights, experiences and expertise. The authors take full responsibility for the interpretations and conclusions of this paper.

\section{Funding}

CG and SL are researchers at the Norwegian Institute of Public Health and were funded by the Norwegian Agency for Development Cooperation (Norad). SL receives additional funding from the South African Medical Research Council. Neither of these funders had any involvement in the design, collection, analysis or interpretation of data, in manuscript preparation or submission. BG is a staff member of the UNDP/UNFPA/UNICEF/WHO/World Bank Special Programme of Research, Development and Research Training in Human Reproduction (HRP), World Health Organization. AS is an independent consultant based in Mexico City, Mexico. AS's work on this study was also funded by this Special Programme.

\section{Availability of data and materials}

The studies used in the synthesis are listed in the references section. Data from the key informant feedback is available on request.

\section{Authors' contributions}

CG, BG and SL designed the study. CG and AS searched for and analysed relevant documentation and carried out and analysed key informant feedback. CG prepared the manuscript with input from AS, BG and SL. All authors read and approved the final manuscript.

\section{Authors' information}

CG, AS, BG and SL undertook this work to inform the World Health Organization $(\mathrm{WHO})$ guidelines on "Health worker roles in providing safe abortion care and post-abortion contraception" [1]. CG and SL are employed by the Norwegian Public Health Institute, and support Norwegian government legislation that grants women the right to request an abortion up until the 12 week of pregnancy. CG and SL are also editors for the Cochrane Effective Practice and Organisation of Care Group and have a particular interest in interventions that can improve health workers' working conditions and the functioning of health systems. BG is the technical lead for safe abortion work at the UNDP/UNFPA/UNICEF/WHO/World Bank Special Programme of Research, Development and Research Training in Human Reproduction (HRP). She has a particular interest in reproductive health research focused on women's perspectives. AS is an Independent Consultant in Reproductive and Sexual Health, with a focus on research and an interest in stigma as it relates to abortion and teenage pregnancy. The views and opinions expressed in this paper are those of the authors and do not necessarily reflect the official policies or views of their organizations.

Ethics approval and consent to participate

Each key informant agreed in writing to contribute and to be acknowledged in the paper. Each key informant saw the final draft of the paper before submission and approved any use of quotes.

\section{Consent for publication}

Not applicable.

\section{Competing interests}

The authors declare that they have no competing interests.

\section{Publisher's Note}

Springer Nature remains neutral with regard to jurisdictional claims in published maps and institutional affiliations.

\section{Author details}

${ }^{1}$ Global Health Unit, Norwegian Institute of Public Health, Oslo, Norway. ${ }^{2}$ Independent Consultant in Reproductive and Sexual Health, Mexico City, Mexico. ${ }^{3}$ UNDP/UNFPA/UNICEF/WHO/World Bank Special Programme of Research, Development and Research Training in Human Reproduction (HRP), World Health Organization, Geneva, Switzerland. ${ }^{4}$ Global Health Unit, Norwegian Institute of Public Health / Health Systems Research Unit, South African Medical Research Council, Cape Town, South Africa. 
Received: 10 April 2017 Accepted: 15 September 2017 Published online: 21 September 2017

\section{References}

1. WHO. Health worker roles in providing safe abortion care and post abortion contraception. Geneva: World Health Organization; 2015.

2. Shakya G, Kishore S, Bird C, Barak J. Abortion law reform in Nepal: women's right to life and health. Reprod Health Matters. 2004;12(Suppl 24):75-84.

3. Jewkes RK, Gumede T, Westaway MS, Dickson K, Brown H. Why are women still aborting outside designated facilities in metropolitan South Africa? BJOG. 2005;112:1236-42.

4. Trueman KA, Magwentshu M. Abortion in a progressive legal environment: the need for vigilance in protecting and promoting access to safe abortion services in South Africa. Am J Public Health. 2013;103(3):397-9.

5. Harries J, Cooper D, Strebel A, Colvin CJ. Conscientious objection and its impact on abortion service provision in South Africa: a qualitative study. Reprod Health. 2014;11:16.

6. Samandari G, Wolf M, Basnett I, Hyman A, Andersen K. Implementation of legal abortion in Nepal: a model for rapid scale-up of high-quality care. Reprod Health. 2012;9:7.

7. Henderson JT, Puri M, Blum M, Harper CC, Rana A, Gurung G, et al. Effects of abortion legalization in Nepal, 2001-2010. PLoS One. 2013;8(5):e64775.

8. Cóppola F. Interrupciòn voluntaria del embarazo y objeción de conciencia en Uruguay. Rev Med Urug. 2013;29(1):36-9.

9. Leitner. Exporting Confusion U.S. Foreign Policy as an Obstacle to the Implementation of Ethiopia's Liberalized Abortion Law New York City. New York City: The Leitner Center for International Law and Justice; 2010.

10. Dixon-Mueller R. Innovations in reproductive health care: menstrual regulation policies and programs in Bangladesh. Stud Fam Plan. 1988;19(3):129-40.

11. Puri M, Tamang A, Shrestha P, Joshi D. The role of auxiliary nurse-midwives and community health volunteers in expanding access to medical abortion in rural Nepal. Reprod Health Matters. 2015;22(44):94-103.

12. Desta D. Senior Program Manager. Addis Ababa, Ethiopia: Ipas Ethiopia; 2014. (personal communication)

13. Mitchell JC. Case and situation analysis. Sociological Review. 1983;31: 187-211.

14. Patton MQ. Qualitative Research and Evaluation Methods. 3rd ed. Thousand Oaks, California: Sage Publications; 2002.

15. SURE. SURE Guides for Preparing and Using Evidence-Based Policy Briefs: 5. Identifying and addressing barriers to implementing policy options. Version 2.1 [updated November 2011]. The SURE Collaboration 2011.

16. Karki C, Ojha M, Rayamajhi RT. Baseline survey on functioning of abortion services in government approved CAC centers in three pilot districts of Nepal. Kathmandu Univ Med J (KUMJ). 2009;7(25):31-9.

17. KC N, Basnett I, Sharma SK, Bhusal CL, Parajuli RR, Andersen KL. Increasing access to safe abortion services through auxiliary nurse midwives trained as skilled birth attendants. Kathmandu Univ Med J (KUMJ). 2011;9(36):260-6.

18. Puri M, Lamichhane P, Harken T, Blum M, Harper CC, Darney PD, et al. Sometimes they used to whisper in our ears: health care workers' perceptions of the effects of abortion legalization in Nepal. BMC Public Health. 2012;12:297.

19. Moller A, Ofverstedt S, Siwe K. Proud, not yet satisfied: the experiences of abortion service providers in the Kathmandu Valley. Nepal Sex Reprod Healthc. 2012;3(4):135-40.

20. Potgieter $C$, Andrews $G$. South African nurses' accounts for choosing to be termination of pregnancy providers. Health SA Gesondheid. 2004;9:2.

21. Harries J, Stinson K, Orner P. Health care providers' attitudes towards termination of pregnancy: a qualitative study in South Africa. BMC Public Health. 2009;9:296.

22. Harries J, Cooper D, Strebel A, Colvin CJ. Conscientious objection and its impact on abortion service provision in South Africa: a qualitative study. Reprod Health. 2014;11(1):16.

23. Engelbrecht MC, Pelser AJ, Ngwena C, van Rensburg HC. The implementation of the Choice on Termination of Pregnancy Act: some empirical findings. Curationis. 2000;23(2):4-14.

24. Harries J, Lince N, Constant D, Hargey A, Grossman D. The challenges of offering public second trimester abortion services in South Africa: health care providers' perspectives. J Biosoc Sci. 2012;44(2):197-208.

25. Harrison A, Montgomery ET, Lurie M, Wilkinson D. Barriers to implementing South Africa'a Termination of Pregnancy Act in rural KwaZulu / Natal. Health Policy Plan. 2000;15(4):424-31.
26. Mitchell EMH, Trueman K, Gabriel M, Fine A, Manentsa N. Accelerating the pace of progress in South Africa, An evaluation of the impact of Values Clarification Workshops on termination of pregnancy access in Limpopo Province. South Africa: IPAS; 2004.

27. Poggenpoel $M$, Myburgh CP, Gmeiner AC. One voice regarding the legalisation of abortion. Nurses who experience discomfort. Curationis. 1998;21(3):2-7.

28. Silva M. Independent Consultant - Medicin du Monde (Medicos del Mundo) and Iniciativas Sanitarias. 12 August 2014 (personal communication).

29. Abdi J, Gebremariam MB. Health providers' perception towards safe abortion service at selected health facilities in Addis Ababa. Afr J Reprod Health. 2011;15(1):31-6.

30. Holcombe SJ, Berhe A, Cherie A. Personal Beliefs and Professional Responsibilities: Ethiopian Midwives' Attitudes toward Providing Abortion Services after Legal Reform. Stud Fam Plan. 2015:46(1):73-95.

31. Das T. Directorate General of Family Planning (DGFP), Bangladesh. 31 August 2014 (personal communication)

32. Sultana S. Senior Advisor -Training and Health Systems, Ipas Bangladesh. 24 August 2014 (Personal communication).

33. Chowdhury SN, Moni D. A situation analysis of the menstrual regulation programme in Bangladesh. Reprod Health Matters. 2004;12(24 Suppl):95-104.

34. Vlassoff M, Hossain A, Maddow-Zimet I, Singh S, Bhuiyan HE. Menstrual Regulation and Postabortion Care in Bangladesh: Factors Associated with Access to and quality of Services. New York: Guttmacher Institute; 2012.

35. Hena IA, Rob U, Sultana N, Irfanhossain MD, Yasmin R, Das TR, et al. Introducing medical MR in Bangladesh. MRM final Report. Dhaka, Bangladesh: Population Council; 2013.

36. ESOG. Ethiopian Society of Obstetrics and Gynecology: KAP study on abortion among Ethiopian health workers. 2002.

37. Ross GC. Sustaining menstrual regulation policy: A case study of the policy process in Bangladesh. London: London School of Hygiene and Tropical Medicine; 2002

38. Harrison A, Montgomery ET, Lurie M, Wilkinson D. Barriers to implementing South Africa's Termination of Pregnancy Act in rural KwaZulu/Natal. Health Policy Plan. 2000;15(4):424-31.

39. Mayers P, Parkes B, Green B, Turner J. Experiences of registered midwives assisting with termination of pregnancies at a tertiary level hospital. Health SA Gesondheid. 2005;10(1):15-25.

40. Mokgethi NE, Ehlers VJ, van der Merwe MM. Professional nurses' attitudes towards providing termination of pregnancy services in a tertiary hospital in the north west province of South Africa. Curationis. 2006;29(1):32-9.

41. Fiol V, Briozzo L, Labandera A, Recchi V, Pineyro M. Improving care of women at risk of unsafe abortion: implementing a risk-reduction model at the Uruguayan-Brazilian border. Int J Gynaecol Obstet. 2012; 118(Suppl 1):S21-7.

42. Nashid T, Olsson P. Perceptions of women about menstrual regulation services: qualitative interviews from selected urban areas of Dhaka. J Health Popul Nutr. 2007;25(4):392-8

43. Alemu FF. Minors' awareness about the new abortion law and access to safe abortion services in Ethiopia: The Case of Marie Stopes International Ethiopia Centers in Addis Ababa. Amsterdam: University of Amsterdam; 2010.

44. Alblas M. Independent sexual and reproductive health right (SRHR) consultant, abortion provider and trainer. Western Cape: South Africa; 2014. (Personal communication)

45. CREHPA. Evaluation of pilot medical abortion initiatives in six districts of Nepal: An endline survey. Kathmandu, Nepal: Center for Research on Environment Health and Population Activities; 2009.

46. Harries J. Director, Women's Health Research Unit. South Africa: School of Public Health and Family Medicine, Faculty of Health Sciences, University of Cape Town; 2014. (personal communication)

47. Hyman AG, Baird TL, Basnett I. Establishing second trimester abortion services: experiences in Nepal, Viet Nam and South Africa. Reprod Health Matters. 2008;16(31 Suppl):135-44.

48. Varkey S. Viewpoint. Abortion services in South Africa: available yet not accessible to all. Int Fam Plan Perspect. 2000;26(2):87-8.

49. Turner KL, Hyman AG, Gabriel MC. Clarifying values and transforming attitudes to improve access to second trimester abortion. Reprod Health Matters. 2008;16(31 Suppl):108-16.

50. Berhe A. Country Midwife Advisor at UNFPA Country Office Ethiopia. 2014 (personal communication). 
51. Labandera A, Gorgoroso M, Briozzo L. Implementation of the risk and harm reduction strategy against unsafe abortion in Uruguay: From a university hospital to the entire country. Int J Gynaecol Obstet. 2016;134(Suppl 1):S7-s11.

52. Tamang A. Director, Center for Research on Environment Health and Population Activities (CREHPA). Nepal: Kathmandu; 2014. personal communication

53. Family Health Department. Technical and Procedural Guidelines for Safe Abortion Services in Ethiopia Addis Ababa, Ethiopia: Family Health Department 2006

54. Labandera Monteblanco A. Presidenta de Federación Latinoamericana de Obstetras, Directora Ejecutiva de Iniciativas Sanitarias., Jefa de Departamento Obstétrico del Hospital de la Mujer del CHPR, ASSE. Montevideo, Presidenta del Tribunal Arbitral de la Asociación Obstétrica del Uruguay. 8 August 2014 (personal communication).

55. Singh M, Jha R. Abortion legalized: challenges ahead. Kathmandu Univ Med J (KUMJ). 2007;5(1):95-7.

56. Tsegay A. Knowledge, attitude and practice of public health practitioners towards safe abortion care services in Tigray regional state, Ethiopia. Sweden: Umeå University; 2011.

57. CREHPA. Increasing awareness and access to safe abortion among Nepalese women: An evaluation of the network for addressing women's reproductive risk in Nepal program. Kathmandu, Nepal: Centre for Research on Environment Health and Population Activities (CREHPA); 2009

58. Hossain A. Mapping of MR programme in Bangladesh. Need emphasis on public-private collaboration. Health And Rights. Oct-Dec 2008;1(4).

59. Andersen KL, Basnett I, Shrestha DR, Shrestha MK, Shah M, Aryal S. Expansion of Safe Abortion Services in Nepal Through Auxiliary NurseMidwife Provision of Medical Abortion, 2011-2013. Journal of Midwifery \& Women's Health. 2016;61(2):177-84.

60. Tamang A, Tamang J. Availability and acceptability of medical abortion in Nepal: health care providers' perspectives. Reprod Health Matters. 2005;13(26):110-9.

61. Akhter $\mathrm{HH}$. Expanding access: midlevel provider in menstrual regulation, Bangladesh experience. [Unpublished] 2002. Prepared for the conference, "Expanding Access: Advancing the Roles of Midlevel Providers in Menstrual Regulation and Elective Abortion Care, Kwa Maritane Lodge, Pilanesberg National Park, South Africa, December 2-6, 2001., 2001.

62. Akhter HH. Current status of policy and access to abortion: The Bangladesh experience. In: Klugman B, Budlender D, editors. Advocating for Abortion Access: Eleven Country Studies Johannesberg. South Africa: The Women's Health Project, School of Public Health, University of the Witwatersrand; 2001.

63. Afework MF, Yeneneh H, Seid A, Belete S, Yimer B, Gizaw A, et al. Acceptability of the Involvement of Health Extension Workers (Hews) in Medical Abortion (Ma): The Perspectives of Clients, Service Providers and Trained Hews in East Shoa and Arsi Zones, Oromiya Region. Ethiopia Ethiop Med J. 2015;53(1):25-34

64. Shrestha M, Andersen K, Pearson E, Basnett I. Provision of induced abortion by nurse providers using manual vacuum aspiration. Presented at the NESOG Conference in Kathmandu. 2011;

65. Mamabolo L, Tjallinks J. Experiences of registered nurses at one community health centre near Pretoria providing termination of pregnancy services. Afr J Nurs Midwifery. 2010;12(1):73-86.

66. Thapa S, Malla K, Basnett I. Safe abortion services in Nepal: initial years of availability and utilization. World Health Popul. 2010;11(3):55-68.

67. Yirga A. Status of safe abortion service utilization and levels of satisfaction in selected public health facilities of SNNPR, Ethiopia, 2008/09. Addis Ababa: Addis Ababa University; 2009.

68. Prata NG A. Holston M. Moran M. Weinrib R. Comprehensive abortion care pilot project in Tigray, Ethiopia: Final report. Tigray Regional Health Bureau, Ethiopia; Venture Strategies Innovations, California, USA; Bixby Center for Population, Health and Sustainability, California, USA, 2011.

69. Orner P, de Bruyn M, Harries J, Cooper D. A qualitative exploration of HIVpositive pregnant women's decision-making regarding abortion in Cape Town. South Africa Sahara J. 2010;7(2):44-51.

70. Harries J, Orner P, Gabriel M, Mitchell E. Delays in seeking an abortion until the second trimester: a qualitative study in South Africa. Reprod Health. 2007:4:7.

71. Caldwell B, Barkat e K, Ahmed S, Nessa F, Haque I. Pregnancy termination in a rural subdistrict of Bangladesh: a microstudy. Int Fam Plan Perspect. 1999; 25(1):34-7. 43

72. Mahmud I, Chowdhury S, Siddiqi BA, Theobald S, Ormel H, Biswas S, et al. Exploring the context in which different close-to-community sexual and reproductive health service providers operate in Bangladesh: a qualitative study. Hum Resour Health. 2015;13:51.

73. Marlow HM, Biswas K, Griffin R, Menzel J. Women's experiences with medication for menstrual regulation in Bangladesh. Cult Health Sex. 2016;18(3):349-60.

74. CREHPA. BCC Strategy Development for Accessing Safe Abortion Care in Nepal: A Formative Needs Assessment. Kathmandu: Kathmandu, Nepal Centre for Research on Environment Health and Population Activities (CREHPA); 2005.

75. Andersen K, Singh A, Shrestha MK, Shah M, Pearson E, Hessini L. Early pregnancy detection by female community health volunteers in Nepal facilitated referral for appropriate reproductive health services. Glob Health Sci Pract. 2013;1(3):372-81.

76. Holcombe SJ. Bixby Associate Fellow. Berkeley, USA: University of California; 2014. (Personal communication)

77. Smit I, Bitzer EM, Boshoff EL, Steyn DW. Abortion care training framework for nurses within the context of higher education in the Western Cape. Curationis. 2009;32(3):38-46.

78. IPAS. Expanding the provider base for abortion care: Findings and recommendations from an assessment of pre-service training needs and opportunities in Bangladesh. 2013.

79. Women's Right to Choose: Parnerships for Safe Abortion in Nepal. Kathmandu Family Health Division, Ministry of Health, His Majesty's Government of Nepal, CREHPA, FWLD, Ipas, PATH 2005.

80. Gabriel M. Program Director, Ipas South Africa. 2014 (Personal communication).

81. Dickson-Tetteh K, Billings D. Abortion Care Services Provided by Registered Midwives in South Africa. Int Fam Plan Perspect. 2002;28:3.

82. Basnett I, Shrestha MK, Shah M, Pearson E, Thapa K, Andersen KL. Evaluation of nurse providers of comprehensive abortion care using MVA in Nepal. J Nepal Health Res Counc. 2012;10(1):5-9.

83. Gmeiner AC, Van Wyk S, Poggenpoel M, Myburgh CP. Support for nurses directly involved with women who chose to terminate a pregnancy. Curationis. 2000;23(1):70-8.

84. Nursing Update. Doctors and nurses reluctant to perform legal abortions Nursing Update. 2000; July.

85. Amin R, Kamal GM, Mariam AG. Menstrual regulation in Bangladesh: an evaluation of training and service programs. Int J Gynaecol Obstet. 1988; 27(2):265-71.

86. Andersen K, Singh A, Shrestha MK, Shah M, Pearson E, Hessini L. Early pregnancy detection by female community health volunteers in Nepal facilitated referral for appropriate reproductive health services. Global Health Science \& Practice. 2013;1(3):372-81.

87. Swartz L, Kilian S, Twesigye J, Attah D, Chiliza B. Language, culture, and task shifting-an emerging challenge for global mental health. Glob Health Action. 2014;7:23433

88. Lewin S, Glenton C, Munthe-Kaas H, Owolabi O, Pileggi V, Sorhaindo A, et al. Evidence base for acceptability and feasibility. Annex 29: Factors affecting the implementation of task-shifting for abortion care: qualitative evidence synthesis. Health worker roles in providing safe abortion care and post abortion contraception. Geneva: World Health Organization; 2015.

89. Glenton C, Colvin CJ, Carlsen B, Swartz A, Lewin S, Noyes J, et al. Barriers and facilitators to the implementation of lay health worker programmes to improve access to maternal and child health: qualitative evidence synthesis. Cochrane Database Syst Rev. 2013;10(10):Cd010414.

90. Gopinathan U, Lewin S, Glenton C. Implementing large-scale programmes to optimise the health workforce in low- and middle-income settings: a multicountry case study synthesis. Tropical Med Int Health. 2014;19(12):1437-56.

91. Colvin CJ, de Heer J, Winterton L, Mellenkamp M, Glenton C, Noyes J, et al. A systematic review of qualitative evidence on barriers and facilitators to the implementation of task-shifting in midwifery services. Midwifery. 2013; 29(10):1211-21.

92. Mijovic H, McKnight J, English M. What does the literature tell us about health workers' experiences of task-shifting projects in sub-Saharan Africa? A systematic, qualitative review. J Clin Nurs. 2016;25(15-16):2083-100.

93. Crowley T, Mayers P. Trends in task shifting in HIV treatment in Africa: Effectiveness, challenges and acceptability to the health professions. Afr J Prim Health Care Fam Med. 2015;7(1):1-9.

94. Jelen TG. C W. Causes and consequences of public attitudes toward abortion: A review and research agenda. Political Research Quarterly. 2003; 56(4):489-500. 
95. Lewin S, Lavis JN, Oxman AD, Bastias G, Chopra M, Ciapponi A, et al. Supporting the delivery of cost-effective interventions in primary healthcare systems in low-income and middle-income countries: an overview of systematic reviews. Lancet. 2008;372(9642):928-39.

96. Wheeler SB, Zullig LL, Reeve BB, Buga GA, Morroni C. Attitudes and intentions regarding abortion provision among medical school students in South Africa. Int Perspect Sex Reprod Health. 2012;38(3):154-63.

97. MoH G. Training non-physician providers to improve postabortion care: Baseline assessment of postabortion care services in four districts of Eastern Region, Ghana. Ghanaian Ministry of Health, Ghana Registered Midwives Association, IPAS, January, 1997.

98. Norris A, Bessett D, Steinberg JR, Kavanaugh ML, De Zordo S, Becker D. Abortion stigma: a reconceptualization of constituents, causes, and consequences. Womens Health Issues. 2011;21(3 Suppl):S49-54.

99. Gallagher K, Porock D, Edgley A. The concept of 'nursing' in the abortion services. J Adv Nurs. 2010;66(4):849-57.

100. Nicholson J, Slade P, Fletcher J. Termination of pregnancy services: experiences of gynaecological nurses. J Adv Nurs. 2010;66(10):2245-56.

101. Parker A, Swanson H, Frunchak V. Needs of labor and delivery nurses caring for women undergoing pregnancy termination. J Obstet Gynecol Neonatal Nurs. 2014;43(4):478-87.

\section{Submit your next manuscript to BioMed Central} and we will help you at every step:

- We accept pre-submission inquiries

- Our selector tool helps you to find the most relevant journal

- We provide round the clock customer support

- Convenient online submission

- Thorough peer review

- Inclusion in PubMed and all major indexing services

- Maximum visibility for your research

Submit your manuscript at www.biomedcentral.com/submit 